\title{
Collectivize Social Support? Elements for Reconsidering the Social Dimension in the Study of Social Support
}

\author{
Esteban Sánchez Moreno \\ Complutense University of Madrid
}

Psychological models of mental disorders play an important role in the explanation of psychological deterioration. Researchers from this area usually study several cognitive and behavioral variables to account for the onset and maintenance of depression. However, many authors have detected the need to include a "social dimension" in the explanation of deterioration. In this sense, social support has become a crucial aspect in the study of mental health, and the psychological literature on this topic has generated an intense debate about several facets of the positive impact of social networks on psychological well-being. In this article, the author defends that this increasing centrality of the concept has been accompanied by a psychological reductionism that is making the role of "social aspects" to explain psychological well-being more problematic. Implications of this reductionism are discussed, and an alternative proposal is made to overcome some theoretical and empirical problems related to social support research.

Keywords: social support, social integration, mental health

\begin{abstract}
Los modelos psicológicos explicativos de los trastornos mentales tienen un papel central en la explicación del deterioro psicológico. Los investigadores en el área suelen manejar algunas variables cognitivas y conductuales para dar cuenta de la aparición y persistencia de la depresión. Sin embargo, numerosos autores han detectado la necesidad de incluir una "dimensión social" en la explicación de dicho deterioro. En este sentido, el apoyo social se ha convertido en un aspecto central para el estudio de la salud mental, y la bibliografía psicológica sobre el tema ha generado un intenso debate en torno a diversos aspectos del efecto positivo de las redes sociales en el bienestar psicológico. En el presente artículo el autor defiende que esta creciente centralidad del concepto se ha visto acompañada por un reduccionismo psicológico que está problematizando el papel de 'lo social' en las explicaciones del bienestar psicológico. Se comentan las implicaciones de este reduccionismo, al tiempo que se realiza una propuesta alternativa para superar algunos problemas teóricos y empíricos relacionados con la investigación sobre el apoyo social.

Palabras clave: apoyo social, integración social, salud mental
\end{abstract}

Correspondence concerning this article should be addressed to Esteban Sánchez Moreno, Departamento de Sociología V, Escuela Universitaria de Trabajo Social. Universidad Complutense de Madrid. Campus de Somosaguas. 28223 Madrid (Spain). E-mail: esteban.sanchez@cps.ucm.es

Translation: Virginia Navascués Howard. 
Is it possible to explain mental illness paying attention exclusively to individual psychological processes? Is it really necessary to include processes of a marked social nature in our explanation of psychological deterioration? These two questions, so easy to answer, may seem like absurd justifications for an article intended to be scientific. All the more so, as the notions expounded herein have the lofty goal of being judged worthy of the attention of the professionals of social intervention when designing their activity. This statement, as well as many others below, is polemic. I am aware of that, and I believe that, in any case, that this polemic is an important element when establishing links between different disciplines and competent viewpoints in the study of social support. On the other hand, the dimensions of an article preclude a detailed analysis of some aspects. (For a more extensive debate about various aspects included in this article see Sánchez Moreno, 1998, 2002a, 2004; Sánchez Moreno \& Barrón, 2003; Barrón \& Sánchez Moreno, 2001, 2003; Sánchez Moreno, Garrido, \& Álvaro, 2001). Assuming the aforementioned risks, I beg readers to be patient, in the hope that when they finish reading the article, they will be won over to the belief that, in the practical design of the analyses of mental illness, the easy answers to both questions conceal a contradiction that is hardly justifiable.

The psychological explanation of mental illness is insufficient. Hence, the need to introduce social processes, to use concepts with a clear social recollection to account for psychological deterioration. Among these processes, social support has been a crucial variable, which is why I dedicate an entire article to it. Social support has been the life boat in which the psychological outlook has tried to escape from the accusation of reductionism. Are social processes necessary to explain mental illness? Of course. Which is the appropriate level to respond to this need? The group level. Why is the group so important for mental illness? Because it is the source of social support.

Despite the protagonism that several authors have lent to the concept of social support, we shall see that the adjective, far from being fundamental, has had in its linguistic acceptance diluted, to wind up reduced to the status of a descriptor in articles: Its substantive nature has been lost in the psychological storm. Let us look into this in more detail.

\section{Social Support}

The history of social support in relation to mental illness is short but intense. Short, because, far from intellectual romanticisms, this concept did not play a relevant role until the mid seventies. Intense, there are such strong disagreements about it that nowadays, almost 30 years later, it is still quite difficult to adequately synthesize the main disputes that have characterized these three decades. Nevertheless, there are some clearly identifiable basic trends. One of them, which I will focus on, has been especially pernicious. I refer to the psychologization of a process that started out as the great sociological hope in the field of mental illness. ${ }^{1}$

The study of social support was integrated into scientific activity with the publication of the works of Cobb (1976) and Cassel (1976). These authors defended the existence of environmental processes of opposite signs regarding an individual's mental health. On the one hand, we have the processes that undermine mental health: Both authors refer to stress. On the other, we can identify processes that perform a protective role: social support. This is a buffering factor of stress, reducing its impact and thus, protecting people from the negative effect of stress. In this way, social support is a process that has a positive effect on people when in the presence, but not in the absence, of stressors. But what is social support? According to Cobb (1976, p. 300 ), social support consists of "information belonging to one or more of the following kinds:

1. Information that leads people to believe they are cared for and loved.

2. Information that leads people to believe they are esteemed and valued.

3. Information that leads people to believe they belong to a network of communication and mutual obligations."

Such information is born within social relations and, therefore, is an emergent property within the groups that comprise people's social networks. In these networks, the individual will find protection from stressing situations, life transitions, destabilizing events that one inevitably encounters throughout one's life. In this sense, the group becomes a sort of armor that people use to protect themselves from the blows to which they are irremediably exposed at some time during their existence. Cobb and Cassel coincided in their analysis. Social support is a group property, whose study is necessarily linked to stress, because its chief role is to protect people from the impact of stress. This original agreement, however, was soon at risk from the subsequent work of researchers of social support. Specifically, one of the most persistent debates is precisely the conceptual debate. Thus, in an argument that is still ongoing, the aforementioned question is constantly repeated: What is social support? The main theory of this article is that, in that debate, the concept has slowly but surely been the object of psychologization that is scarcely justifiable.

\footnotetext{
1 Therefore, the reader should not expect a discussion of certain aspects that are just as relevant. For example, I will not analyze the models used to explain the activity of social support (hypothesis of direct effects and hypothesis of buffering effects), except when the line of reasoning requires me to do so.
} 
In general, researchers do not agree about the definition of social support (Cohen, 1988). This discrepancy has become notably encysted, with various co-existing viewpoints of the concept of social support in the research. According to Barrón (1996), there are three relevant aspects in the definition of social support:

First, the level of analysis chosen: communitary level, social networks, close relationships.

Second, the study outlooks: structural, functional, and contextual.

Third, the definition of social support will depend on whether emphasis is placed on the objective or the subjective aspects.

All these aspects are important in the conceptual analysis of social support. However, in this explanation, I will emphasize the aspects revealed as the most relevant in the current bibliography.

As is well known, there are two main perspectives of the study of social support, functional and structural. As mentioned, there is a third viewpoint, the contextual (Vaux, 1988). However, research has developed in the first two. In addition, these are one of the areas that, according to Cohen and Syme (1985), need clarifying and are crucial for the development of research in social support. Therefore, I shall comment on them in the following paragraphs.

The structural viewpoint focuses on the existence, quantity, and properties of a person's social relations. In the analysis of social contacts, it focuses on the study of structural aspects, ignoring in most cases, the functions performed by those contacts.

From this perspective, it is assumed that maintaining social relations implies the existence of social support (that is, transactions with a beneficial effect on well-being). Research has therefore focused on determining which network characteristics are more beneficial and effective for the individual's well-being (Stoller \& Pugliesi, 1991). Hence, a series of characteristics of the support network are typically studied from this viewpoint, among them, the following: size, density, reciprocity, duration, intensity, frequency, dispersion, and homogeneity (Barrón, 1996).

The second perspective, the functional perspective, emphasizes a different aspect of social relations. It attempts to identify which of the individual's functions are satisfied by the relations. The qualitative aspects of support are therefore underscored. I refer to a transaction (symmetrical or not) of resources (ranging from money to affection) oriented to the satisfaction of a need. In this sense, some authors (House \& Kahn, 1985) define social support as the functional contents of social interactions, distinguishing it explicitly from other concepts such as social relations or support networks. In other words, the functions performed by social interactions for the person who receives support are specific to social support.

Several social support functions have been indicated (see Wills, 1985; Farrell, Barnes, \& Banerjee, 1995). Basically, they can be grouped into three types.
1. Emotional support involves having someone to talk to, someone to whom one can talk about one's problems, etc. Normally, it refers to the assistantial functions carried out by family, friends, work colleagues, neighbors, or any significant person. It includes expressions of love, affection, attraction, esteem, etc., that produce a feeling of affective well-being.

2. Instrumental support is made up of help that affects a need involving either some lack of material resources (money, living quarters, etc.) or solving everyday problems (caring for children, helping at home, etc.).

4. Informational support consists of useful advice, information, or guidelines to cope with important life changes or to give meaning to the world.

Summing up, this perspective defends the existence of a series of functions performed for individuals by members of their support network. Obviously, these functions are born within the social relations and, therefore, one could expect a strong connection between the measurements based on either of these perspectives (structural and functional). However, reality does not conform to this assumption. In fact, the debate between these perspectives has ramifications that go beyond conceptual aspects. But, at present, my intention is only to show the general framework in which were developed the main attempts to offer an operative definition-adequate to the needs of research-of social support.

\section{Social Support?}

And here is where the psychologization tendency of social support starts. This tendency is mainly expressed by authors who endorse the second perspective, the functional viewpoint. Obviously, it is difficult to turn a definition of social support, based on the structural characteristics of the support network, into a psychological construct. The size, density of the contacts within the network, etc., are characteristics that are not imputable to individuals, but instead to their relational context.

However, the functional perspective has proved to be especially rich in possibilities of dissent. Such dissent is not negative in itself, of course. On the contrary, it facilitates the vigorous development of the concept of social support. The truly negative aspect for the study of mental health is the course that this dissent has taken in the conceptualization of social support and group relations in general. In this section, some of the proposals that have had most impact on research in the area will be analyzed; proposals that, as the reader will observe, are characterized by progressive individualization of social support.

I shall start with the contribution of Lin, Dean, and Ensel (1986). Considering that intimate relations are the most important aspect of social support, these authors offer a definition based on the strength of the ties with close groups. Social resources are the starting point of social support. 
Thus, maintaining adequate levels of mental health requires sharing experiences and exchanges with persons from the context of a close relationship. These people would be more capable of understanding the individual's problems. This viewpoint reveals the expressive nature of support activities (according to the authors, necessary to maintain some level of psychological well-being). These expressive actions involve the basic content of intimate relationships.

To sum up, access and use of strong ties with similar persons (principle of homophilia) would comprise the central nucleus of social support. This definition is based on the need for strong ties within the framework of intimate relations (strong-tie support). The main aspect of social support would thus consist of providing expressive actions within the framework of intimacy. The authors have used the operationalization of this concept in a series of studies (Dean \& Ensel, 1982; Dean, Kolody, \& Wood, 1990; Lin \& Ensel, 1984, 1989; Lin, Woelfel, \& Light, 1985), revealing how the expressive actions that are typical of intimate relations are a beneficial influence for psychological wellbeing.

Some of the concepts that emerged during the eighties increased the individual weight of social support. In this sense, the concept of "Support Bank" (Antonucci, 1985; Antonucci \& Akiyama, 1987; Antonucci \& Jackson, 1990) is a great step towards psychologization of the study of social support. It refers to social support as a "bank account," with its respective debits and credits. These credits and debits are influenced by sociodemographic variables and determined by early experiences. A concept of social support based on the perception of the subjects involved is thus established. Similarly, the "balance," generated within the exchange framework and influenced by the perception of equity, becomes part of the personality. Similarly, situations of (in)congruence between perception and receipt of support are established. In this case, such (in)congruence is presented in terms of balance. The most important aspect of this balance is found in the individual who manages it, because social support, as defined by the authors, is not very different from a savings book issued by any bank to an account holder. One perceives that one receives and gives, one obtains the relation between credits and debits, and the result is "one's social support." This is not an emergent property of social relations; it does not appear in the course of interaction. This is very important. Despite the fact that the balance of support results from adding credits and debits, its nature actually emerges prior to group relations and focuses on the particular relation that one individual has with the rest of the members of his group, one by one. Social support, conceived as balance, or in terms of support bank, can only be defined as the result of adding and subtracting credits and debits that the actor receives or suffers with individual A from his group, plus the result of adding and subtracting credits and debits with respect to individual B, plus the result of adding and subtracting credits and debits with respect to individual C... Ultimately, social support could be conceived as a mathematical function like the following:

$$
A S \cong(I+G)_{1}+(I+G)_{2}+\ldots+(I+G)_{n}
$$

To exaggerate the claim, it could be pointed out that social support is the combination of additions and subtractions that the individuals carry out when thinking about their relations with each of the individuals that comprise their social network. We carry support in our pockets, whether we are rich or whether we only have a few cents.

Although it may seem difficult, other definitions reinforce the individual nature of social support even more. According to some authors, social support should be strictly considered a personality variable. In a series of works, Sarason and colleagues (Pierce, Sarason, Sarason, Joseph, \& Henderson, 1996; Sarason, 1988; Sarason \& Sarason, 1985; Sarason, Sarason, \& Pierce, 1992; Sarason, Sarason, \& Shearin, 1986) attempt to determine the nature of intraindividual social support. Their concept is based on observing the primacy of the perception of support on mental health. That is, their elaboration is based on the consideration of perceived social support (see Sarason, Pierce, \& Sarason, 1990). According to Sarason (1988), it is important to establish the place that social support occupies with regard to the individual. On the one hand, social support could be placed (and act as) over the individual and, therefore, would be an external variable (or, at least, psychosocial). On the other hand, social support could be a function of personal attributes (or, negatively, a lack of social skills). The authors prefer the second option. Social support is comprised of an individual immersed in a series of relationships with different levels of depth. The feeling of being loved and valued, according to these authors, is the chief protective component.

In order to defend the concept of social support as a developing personality variable, the authors resort to Bowlby's $(1969,1986)$ attachment theory. According to this author, early experiences, especially the experience of a secure and unmenaced relation with a paternal figure, are necessary to develop subsequent satisfactory relations. A secure and satisfactory relationship promotes the pattern of exploring the environment. Once these patterns are established, and for the rest of the individual's life, a person is likely to show the same behavioral pattern, leaving loved ones and going far away and for increasingly longer periods of time, but always keeping in contact and sooner or later, returning. The base from which an adult operates will probably be his original family or any other base that he has created for himself. Anyone who lacks a base will feel uprooted and intensely lonely (Bowlby, 1986). Both patterns, the attachment pattern and the exploration pattern, alternate in healthy individuals. 
On the basis of the attachment theory, Sarason et al. articulate their concept of the sense of support. Knowing that others love us and are available is what makes up the essence of social support. This feeling of support is related to another personality characteristic, the sense of acceptance. This refers to the belief that others love and care for us, accept us as we are, including our best and worst parts (Sarason, Sarason, \& Pierce, 1992). The sense of acceptance is generated in the inferences about the self, related with, but not necessarily involved in, the sense of support.

These personality characteristics wind up acting as independent variables in individuals' behavior. In recent reports, the authors (Sarason, Sarason, \& Pierce, 1992) defend what they call a triad hypothesis. This consists of three contexts-personal, interpersonal, and situational-in the analysis of the sense of support. However, both the sense of support and the sense of acceptance are still parts of personality, although they are considered products of the individual history of social interactions (especially in the early patterns of attachment and exploration). According to these authors' reasoning, both personality patterns influence the way people cope with different types of situations.

This is one more turn of the screw, another twist of the spiral that, little by little, deprives social support of all its social characteristics. This does not refer to characteristics of the social network, nor the functions that develop in social relationships. Social support is just another characteristic of the individual's personality, like cognitive styles or extroversion, and should be considered similarly. The implications of this definition of support can lead to awkward reasoning. For example, consider a person who has just emigrated from his original country, and who arrives in Spain knowing practically nobody, except a few persons. Objectively, one could say that his support network is especially restricted, if not nonexistent. Consequently, it is almost common sense to say that the levels of social support that this person might enjoy would be particularly low. However, if we use the outline designed by Sarason's group as our compass, we might make the paradoxical discovery that the recently arrived emigrant may benefit from high levels of social support... despite not having a minimal relational network! In other words, if we use the definition these authors provide, a person in a clearly isolated situation could score high in social support, because this is only a personality trait, an intraindividual characteristic. Once again, the adjective "social" seems to be exclusively a linguistic artifice.

To sum up, we find a scenario that, slowly but surely, has become a sort of funnel in which social relations have been irremediably retained by the narrow part and, social support, flowing down the drain, has been separated from them. That is, theorization on social support has wrenched away its nature of being an emergent process in social relations, until it wound up defining it in exclusively psychological terms. What is left over is a concept of social support completely separated from the hope it originally was. At some point in the research on mental illness, researchers' dissatisfaction with the incapacity of individual and environmental processes to explain psychological deterioration forced them to look at certain social processes in order to find the clues they needed so they could offer a precise outlook of the way to deterioration. Unfortunately, the promise of resolution that researchers hoped to find in social support seems to have been broken. To a great extent, this disappointment has been concealed in the many debates about social support that have appeared in the specialized literature. These debates have generated innumerable works, theoretical and empirical, books, and articles in specialized journals offering interested researchers a vast amount of bibliographic material to support their work. However, this potentially fruitful debate, susceptible of generating important advances in our understanding of the social and psychological processes that lead to mental illness, has become an impenetrable forest where, rather than discovering, we seem instead determined to conceal the aforementioned scientific frustration. But the fundamental paradox consists of the fact that the debate is precisely what has guided our steps towards desiccated areas of knowledge, where arguments have no meaning because they no longer have the same object. I am not referring to irreconcilable antinomies, but to radically different—-but related—levels of analysis, the very specificity and difference of which offered the possibility of enhancing our understanding of psychological deterioration.

Within this context, it is not surprising to observe the appearance of proposals that wind up turning around the argumentative logic, for example, the work of Baumeister and Leary (1995). According to these psychologists' hypothesis, the need to belong is a basic need of human beings, which acts as a fundamental motivational mechanism. People have the motivation to make and keep at least a minimum amount of long-lasting, positive, and significant interpersonal relations. In order to satisfy this need, frequent and satisfactory interactions with other persons are necessary, and, in addition, these interactions should be characterized by temporal stability and should develop within the framework of affective concern for the well-being of the individuals involved in the interaction. This kind of interactions produces a relational setting that promotes the perception of strong ties of interdependence, an essential factor for the satisfaction of the need to belong. The authors propose that this motivational factor is innate in human beings, a result of the process of evolution, and difficult to eradicate culturally. According to Baumeister and Leary (1995), the result of this natural evolutional process would be a series of internal mechanisms that lead the individual to form social groups and long-lasting personal relations. And within this general context-the context of a need that has emerged over the course of evolution, and has become a part of the biological equipment of the human speciesis social support. 
On close examination of these authors' reasoning, the argumentative twist can be clearly observed. Social support changes its status in our general explanatory model. We no longer have to account for its effect on the individual, but instead, the constitution of the species should explain why individuals become involved in social relations. If we look for the company of others, we give and receive affection, we establish intimate relations, we join social networks...in short, if we are social beings, it is because our evolution as a species impels us to do so. Social support is therefore not a consequence of our constitution as members of a species. Once we have deprived social support of its social nature, we return to the Aristotelian argument—we are social beings by nature-but stripping it of all its elegance.

\section{Once again, "social" support?}

If we agree that when we focus on a concept only to deprive if of its distinctiveness, what we are really seeking is, at best, an error (and at worst, an absurdity), then we need to look for solutions. We can present an inflamed defense of the aforementioned structural perspective. In this sense, social support is defined as the structural properties of an individual's support network. However, for various reasons, this solution does not seem satisfactory. First, to adopt this stance means that social support is reduced to the bare description of the traits of the groups where the individual's life evolves: how many friends and family members a person has, the frequency with which he sees them, the density of the support network, and the homogeneity of its components, etc. Second, and consequence of the above, we would be assuming that any social relation is a source of support, which is a particularly risky assumption (Lakey \& Heller, 1988). Not all social relations act as buffers against life events or negative situations. These relations may even become stressful (marital discord, for example). In a study, Haines and Hubert (1992) found that the increase in the size of the network was harmful for the women in their sample. In other words, the women with larger networks revealed higher levels of stress. This study shows that the multiplicity of ties may involve the need to spend more time, energy, and resources to preserve a series of complex relations. Ultimately, the relations became problematic, and the women's overfull agendas - the object of Haines and Hubert's study — was a source of stress. Then again, if we ignore the content of social relations, we run the risk of grouping notably different realities under the same concept. Thus, according to the structural perspective, a married person's family support network is larger than that of a divorced person. One might conclude that marriage is an indicator of high levels of social support. But what about conflictive marriages? In this case, interaction is not a source of support, but quite the contrary, a source of stress.

Summing up, measurements based on a structural perspective tend to use indicators that do not guarantee the existence of support-generating relations. In any case, the analysis of social networks and the structural context of social support is a necessary task, which has made important discoveries for understanding the influence of social relations on people's well-being (see Barrón, 1996). But it is not a solution to the dilemma I have mentioned in this article because social support is not a characteristic of the individual, nor is it the same as the morphological traits of the social network. In fact, social support is an emergent characteristic of social relations, where it is generated and it develops, and from whence it arises. But social support is not the same as social relations. Social support is the result of interaction (a certain kind of interaction) carried out in a subject's relational context. Just as wine is not the same as the bottle, social support is not the same as the support network. I am talking about content, not the container.

Is it impossible, then, to offer a proposal that is more adequate to the process of the concept in question? Obviously, the answer is negative. But perhaps the most sensible solution would be to systematize the characteristic traits that have accompanied the aforementioned estrangement process of the concept of social support and to find the remedy therein:

1. The definition and empirical operationalization of social support is characterized by ever increasing psychologization, even being considered a personality variable by some authors.

2. Along with this process of psychologization, some agreement seems to have been reached about the multidimensional nature of social support (Cohen \& McKay, 1984; Diaz-Veiga, 1993; Laireiter \& Baumann, 1992; Vaux, 1988). This is a meta-construct, the investigation of which has revealed the need to generate more molecular concepts included within it. And this persistence in progressively reducing social support to microscopic elements has clearly led researchers to forget its eminently social nature.

3. In this process, one can observe how some theoriestheories that are the scaffolding on which the work on social support has been established - operate, more or less explicitly. Specifically, I refer to a certain manner of conceiving social relations, which proceeds from the exchange theory. It is impossible to perform an exhaustive analysis of this theory and its diverse forms in these pages. Suffice to observe that the conception of social relations that the exchange theory deals with is extremely individualist (see Thoits, 1983, 1995). Based on behaviorist principles, the exchange theory states that individuals rationalize their social interaction in terms of costs and rewards. In their emphasis on rescuing the individual for Sociology, authors like Homans (1968) attempted to explain social relations in terms of psychological principles. These would be the foundation of social interaction. Hence, a scenario is offered where several actors participate isolatedly in the interaction, lending priority to the dyadic analysis. Therefore, the essence of social relations is not comprised of sociological principles, emerging within the contract that develops in the midst of groups, but instead 
social relations are explained as being solely the sum of interactions of each individual with other individuals, isolatedly, and in psychological terms. In other words, the notion of community in the analysis of social processes is substituted by that of rational, planned, and individual-directed cooperation. Thus, social behavior consists of an exchange of activity, either tangible or intangible, more or less gratifying or ungratifying, between at least two persons: the essence of social support as it has been defined typically in the above-mentioned bibliography (see, as an example, Chipuer, 2001).

These are the distinctive traits of a process that seems to have led us to a dead end, so perhaps the reversal (obviously avoiding a reductionism of the opposite sign) of this tendency would allow research to proceed in a different direction. Hence, rather than segmenting social support into increasingly more basic (supposedly) elements, it seems pertinent to coordinate a general discussion to tackle the definition of social support from a global perspective, and thereby recover its eminently relational nature. To a great extent, this recovery could depend on the use of theories that deal with social aspects from a decidedly sociological viewpoint. The question is the following: What would the result of our discussion be if, instead of using theories in which social relations are defined exclusively as relations between atomized individuals, we used as our model or assumption the theories in which social relations are dealt with from a truly sociological perspective? In the following pages, I will attempt to answer this question through the analysis of the concept of social integration.

Social Support as the Correlate of Social Integration: The Collective Dimension in the Study of Mental Illness

At first glance, it seems difficult to perform an accurate analysis of social support without referring to the concept of social integration. However, the pyramid that holds the conceptual labyrinth where social support was lost may be the result of not using certain privileged material to cast light on the nature and effects of social support: the material provided by Sociology. We run the risk of becoming Egyptologists searching for a terminological sarcophagus -where social support would rest, mummified, immune to the passage of time- to find the clues that would help us to understand how it all started. I propose that the concept of social integration is one of those materials out of which a coherent explanation of social support could be built without resorting to artifices and terminological spirals, or to the aforementioned increasing atomization, or to locking the nature of the concept into a psychological labyrinth from which it is impossible to escape.

Many sociologists have been concerned with the analysis of the concept of social integration. However, given the terms in which the debate is set out, it seems prudent to resort to the works of one of the classic authors within the discipline. In this sense, perhaps the proposals of Emile Durkheim $^{2}$ are more promising for the aims of this article. Throughout his analyses of suicide (Durkheim, 1897/1976), the religious phenomenon (Durkheim, 1912/1982), or changes in the structure of societies (Durkheim, 1893/1982), this classic Frenchman turns social cohesion into the protagonist of his theoretical outlines, through the concept of social solidarity. Solidarity would be comprised of the ties among individuals and between individuals and their community. I refer, basically, to symbolic ties. In other words: Within human societies, cohesion is inextricably linked to the presence of values, traditions, and institutions that lend meaning to behavior, provide content to interaction in daily life and to the way that each society is capable of maintaining its structure, generating solid strategies to administer the basic evaluative consensus that is the nucleus of social integration.

Thus, the analysis of social cohesion carried out by Durkheim reveals two components: the moral one and the normative one. The former refers to the integrative dimension itself. Thus, the moral component refers more to the cultural contents that organize social group life and provide the prime material of which members of a society weave their basic agreements (and their disagreements). The normative component would be responsible for the specific forms of social organization. Solidarity would be the result of both processes. This terminological plurality may lead to confusion in the analysis I propose to carry out, so that hereafter, I shall consider that the moral and normative components are the basic dimensions of social integration (which, as can be seen, implies cultural elements to a great extent): Thus, the social context could be described in terms of the contents of the interaction and norms that preside over it. At this point, I want to emphasize that the use of Emile Durkheim's ideas is a starting point, an example of the possibilities that a certain manner of understanding and conceptualizing social integration offers for the analysis of social support. It is not meant as a finished definition. It is not an alternative definition of social integration. The goal is to extract the fundamental traits from the proposed approach so as to respond to the problem expounded in the previous section. In other words, the formal definition is not what matters, but instead the perspective from which it is formulated (for a detailed analysis, see Sánchez Moreno, 2002b).

2 The analysis of Durkheim's work is not the objective of this study. The reader may, among others, consult the works of Lukes (1984) and Rodríguez Ibáñez (1989). 
What would be the potentialities of my proposal for the study of social support? First, the possibility of conceptual clarification. As mentioned, there are two basic approaches in the study of social support; structural and functional. The structural perspective focuses on the characteristics of the individual's support network: number of members of the relational network, contact frequency and network density, duration and intensity of contacts, homogeneity of network members... And precisely these characteristics have been offered as indicators of social integration. If an individual has more relations of certain frequency and duration, etc., then he is more integrated. If the network shrinks, the contacts are less frequent and extremely heterogeneous, the individual is less integrated. Now then, the analysis of Durkheim's proposals shows that these traits are clearly insufficient to account for integration, ${ }^{3}$ in a dual sense.

First, if we start out from a Durkheimian viewpoint (or better still, a sociological one), it is virtually impossible to accept that integration is a process extending from the individual facet to the social facet. The agreement (sometimes explicit), present in the bibliography on social support and consisting of identifying the "structural" characteristics of the support network with social integration, is a clear confusion of levels of analysis. The description of integration refers to the sum of the characteristics of the individual's network taken one by one. In this sense, the recipe derived from this conception is clear: If an individual is not integrated, it is because this person has few friends, family networks are narrow, and work relations are insufficient. Metaphorically, in this approach, social integration is notably similar to a telephone agenda in a person's wallet. The more telephone numbers on the list, the more integrated the individual will be. In other words, the process is unidirectional, and extends, patently, from the individual facet to the social facet. The consequence is clear: Despite the fact that the term "social integration" is used, we are actually referring to "something" that is more like "individual integration."

To attain a rigorous understanding of social integration, it is necessary to emphasize its true sociological dimension. Social integration is not a sum of members, contacts, relations, etc., because one of the central elements of this concept is comprised, precisely, of the ties that link individuals, making social relations possible. In this sense, I would refer instead to the term "cohesion," what Durkheim would call moral (to a great extent cultural) aspects of society. And, therefore, social integration transcends the individual level of analysis. It is a supraindividual reality, an emergent element of community life. At this point, the confusion in the aforementioned level of analysis is revealed: If we use a psychological-individual level of analysis to account for a process that is at least to some extent social, we renounce understanding and incorporating into our analysis of mental health our starting point, that is, concern with the social dimension.

In addition, fruit of this confusion in the levels of analysis, the second insufficiency appears, imputable to research on the relations between social support and mental health. This insufficiency is condensed in our incapacity to respond adequately to the following question: What are the components of social integration? The predominant viewpoint in the study of social support reveals that the defining traits of social integration are the network characteristics (size, density, etc.). However, if we accept this argument, these characteristics do not complete the definition of the concept. In fact, they may leave out some fundamental elements that would allow us to make sense of the integration processes: norms, values, shared beliefs, collective representations...The importance of this omission is much more serious than would seem because, while brandishing a concept (social integration) with clear sociological connotations, we forget one of the key elements required to understand the concept itself, societies, and the very constitution of Sociology. In the above pages, I referred to the concept of culture. ${ }^{4}$ To talk about integration without mentioning its cultural dimension is almost impossible, with the aggravating circumstance that the solution to this problem is as simple as resorting to one of the founding fathers of sociology. In our case, we look to Durkheim to understand integration as a process that starts out with the community and takes shape in individual behaviors, and not vice versa (see, for example, Martínez, García, \& Maya, 2001). Integration goes beyond belonging to one or another network, and refers to the sociocultural context that presides over individual life and lends meaning to individual and group life, provides content for existence, and is way of access to an intelligible world.

This analysis reveals even more potentialities. For example, it offers the possibility of working fruitfully from a global concept, thus avoiding subdivisions ad infinitum in our analysis of social relations. As mentioned, one of the reactions to the debates generated by the difficulties encountered in research on social support has been to defend the multifaceted nature of social support. Thus, the response has led to an increasingly pronounced dissection of the concept. For example, Laireiter and Baumann (1992) indicate a series of dimensions that, according to them, define social

\footnotetext{
3 Still more, we would find a whimsical use of the concept of social integration. See, for example, Seeman, Lusignolo, Albert, and Berkman (2001).

4 Perhaps the true problem is the difficulty of translating into measuring instruments of all these dimensions of culture. Social norms, shared beliefs, collective values...resist their operationalization into questionnaire items. However, this difficulty does not justify the amputation that the concept of social integration has suffered.
} 
support. Social support would be the compendium of the following processes:

1. Social integration.

2. Social networks.

3. Resources of the support network.

4. Supportive climate.

5. Perceived support.

5.1. Cognitive aspects

5.2. Evaluative aspects

6 . Received or activated support.

Along with the aforementioned obvious confusion of levels of analysis, this segmentation into (again, supposedly) basic elements has, to a great extent, contributed to the psychologization of the social dimension of mental illness. In contrast, the viewpoint defended in this article indicates that a more appropriate way to solve the theoretical and empirical problems in the area is precisely the opposite. It is not necessary to make more and more divisions to decrease the confusion. Specifically, my analysis shows that an adequate definition of the concept of social integration, taken in all its complexity, paradoxically simplifies (insofar as it throws light on) the study of social support. Actually, there are three essential concepts in this task: social integration, social support itself, and social relations. The first refers to the social context in which group life takes place. Obviously, this group life is embodied in social relations, in significant interactions wherein social support is developed. This would be merely the functional result of interaction within social groups. Therefore, social support maintains a basically psychosociological nature, thanks not so much to psychologization, but instead to its insertion into a framework of supraindividual, sociological analysis. In this way, social support could be defined as the functional contents (informational, emotional, and instrumental support) that develop in the midst of social relations. ${ }^{5}$

Last but not least, this modification of the viewpoint of social integration facilitates a new outlook on social relations, which can no longer be considered in behavioral terms, or as exclusively dyadic relations. As mentioned, this conception, derived from overconfidence in the exchange theory, is a constant in the various conceptual (and empirical) approaches to social support. The problem is that social relations have been conceived apart from the culturally given social environment, referring more to individual relations, a notion that leads to a description of a restricted social environment (and, consequently, no longer social). Higher sensitivity towards sociological proposals reminds one that group life-association-is a process that extends beyond the sum of individual behaviors, whether or not they are characterized by exchange. I refer to the emergent properties of social relations, those processes that develop not as a consequence of individualized exchange, but as a result of social interaction understood in a broad sense, as a reality in which individuals do act, but in a much broader cultural, associative, and interactive setting (in conceptual and empirical terms). As Durkheim said: the social entity creates realities. So, if social support is a product of social relations, and these are understood in a restricted sense as individual exchanges (i.e., exchanges between pairs of individuals) governed by psychological principles, then social support will also be understood in a restricted, limited, insufficient sense; because social support is precisely an emergent property of social relations. To refuse to understand this point implies locking up social support in a conception that prevents explaining the processes that make intelligible sense of its nature and effects. This prevents one from considering the meaning of the adjective "social" in all its implications.

The preceding pages are an attempt to show the inconsistencies that have led to the diagnosed situation in the analysis of the intellectual construction of a concept (social support) that is, a priori, essential to understand the onset of mental illness. Specifically, I attempted to show the implications that a higher level of sensitivity towards a sociological viewpoint would have (and, in fact, it do have) in our consideration of social support, by means of the introduction of a particular concept of social integration. Fruit of the elaboration of the implications of this conceptual scheme, the notable benefits observed in the debate on the effects of social support have been revealed. These benefits are specified in three large areas: redirecting the polemic between structural and functional viewpoints of social support, preventing excessive atomization of the concept of social support, and reconceptualizing social relations based on their strictly sociological nature. Altogether, the aim is to redirect psychologization towards a complete understanding of the social entity as a central factor to explain the onset of psychological deterioration.

\section{References}

Antonucci, T.C. (1985). Personal characteristics, social networks and social behavior. In R.H. Binstock \& E. Shanas (Eds.), Handbook of aging and the social sciences (pp. 94-128). NY: Van Nostrand Reinhold.

Antonucci, T.C., \& Akiyama, H. (1987). Social networks in adult life and a preliminary examination of the convoy model. Journal of Gerontology, 42, 519-527.

Antonucci, T.C., \& Jackson, J.S. (1990). The role of reciprocity in social support. In B.R. Sarason, I.G. Sarason, \& G.R. Pierce (Eds.), Social support: An interactional view (pp. 173-198) NY: Wiley.

5 Whether social support is received or perceived, objective or subjective, etc., is a debate that must be solved in the operationalization process. 
Barrón, A. (1996). Apoyo social. Aspectos teóricos y aplicaciones. Madrid: Siglo XXI.

Barrón, A., \& Sánchez Moreno, E. (2001). Estructura social, apoyo social y salud mental. Psicothema, 13, 17-23.

Barrón, A., \& Sánchez Moreno, E. (2003). Alienación, apoyo social y depresión. Encuentros en Psicología Social,1, 225-229.

Baumeister, R.F., \& Leary, M.R. (1995). The need to belong: Desire for interpersonal attachments as a fundamental human motivation. Psychological Bulletin, 3, 497-529.

Bowlby, J. (1986). Vínculos afectivos: formación, desarrollo y pérdida. Madrid: Morata.

Cassel, J. (1976). The contribution of the social environment to host resistance. American Journal of Epidemiology, 104, 107-123.

Chipuer, H.M. (2001). Dyadic attachments and community connectedness: Links with youths' loneliness experiences. Journal of Community Psychology, 29, 429-446.

Cobb, S. (1976). Social support as a moderator of life stress. Psychosomatic Medicine, 38, 300-314.

Cohen, S. (1988). Psychosocial models of the role of social support in the etiology of physical disease. Health Psychology, 7, 269297.

Cohen, S., \& McKay, G. (1984). Social support, stress, and the buffering hypothesis: A theoretical analysis. In A. Baum, S.E. Taylor, \& J.E. Singer (Eds.), Handbook of psychology and health. Vol. IV. Social psychological aspects of health (253-267). Hillsdale, NJ: Erlbaum.

Cohen, S., \& Syme, S.L. (1985). Issues in the study and application of social support. In S. Cohen \& S.L. Syme (Eds.), Social support and health (pp. 3-22). Orlando, FL: Academic Press.

Dean, A., \& Ensel, W.M. (1982). Modelling social support, life events, competence, and depression in the context of age and sex. Journal of Community Psychology, 10, 392-408.

Dean, A., Kolody, B., \& Wood, P. (1990). Effects of social support from various sources on depression in elderly persons. Journal of Health and Social Behavior, 31, 148-161.

Díaz-Veiga, P. (1993). Desarrollo de la evaluación del apoyo social. In M.F. Martínez (Ed.), Psicología Comunitaria (pp. 173-186). Madrid: Eudema.

Durkheim, E. (1982). La división del trabajo social (C.G. Posada, Trans.). Madrid: Akal. (Original work published 1893).

Durkheim, E. (1976). El suicidio (L. Díaz Sánchez, Trans.). Madrid: Akal. (Original work published 1897).

Durkheim, E. (1982). Las formas elementales de la vida religiosa. El sistema totémico en Australia (R. Ramos Torre, Trans.). Madrid: Akal. (Original work published 1912).

Farrell, M.C., Barnes, G.M., \& Banerjee, S. (1995). Family cohesion as a buffer against the effects of problem-drinking fathers on psychological distress, deviant behavior, and heavy drinking in adolescents. Journal of Health and Social Behavior, 36, 377-385.

Haines, V.A., \& Hubert, J.S. (1992). Network range and health. Journal of health and Social Behavior, 33, 254-266.

Homans, G.C. (1968). El grupo humano. Buenos Aires: Eudeba.

House, J.S., \& Kahn, L. (1985). Measures and concepts of social support. In S. Cohen \& S.L. Syme (Eds.), Social support and health (pp. 83-108). Orlando, FL: Academic Press.
Lakey, B., \& Heller, K. (1988). Social support from a friend, perceived support, and social problem solving. American Journal of Community Psychology, 16, 811-824.

Laireiter, A., \& Baumann, U. (1992). Network structures and support functions: Theoretical and empirical analyses. In H.O. Veiel \& U. Baumann (Eds.), The meaning and measurement of social support (pp. 33-55). NY: Hemisphere Publishing Corporation.

Lin, N., Dean, A., \& Ensel, W.M. (1986). Social support, life events and depression. NY: Academic Press.

Lin, N., \& Ensel, W.M. (1984). Depression-mobility and its social etiology: The role of life events and social support. Journal of Health and Social Behavior, 25, 176-188.

Lin, N., \& Ensel, W.M. (1989). Life stress and health: Stressors and resources. American Sociological Review, 54, 382-399.

Lin, N., Woelfel, M.W., \& Light, S.C. (1985). The buffering effect of social support subsequent to an important life event. Journal of Health and Social Behavior, 26, 247-267.

Lukes, S. (1984). Emile Durkheim. Su vida y su obra. Madrid: CIS/Siglo XXI.

Martínez, M.F., García, M., \& Maya, I. (2001). Una tipología analítica de las redes de apoyo social en inmigrantes africanos en Andalucía. Reis, 95, 99-125.

Pierce, G.R., Sarason, B.R., Sarason, I.G., Joseph, H.J., \& Henderson, C.A. (1996). Conceptualizing and assessing social support in the context of the family. In G.R. Pierce, B.R. Sarason, \& I.G. Sarason (Eds.), Handbook of social support and the family (pp. 3-23). NY: Plenum Press.

Rodríguez Ibáñez, J.E. (1989). La perspectiva sociológica: historia, teoría y método. Madrid: Tecnos.

Sánchez Moreno, E. (1998). Apoyo social, integración social, y salud mental. Revista de Psicología Social, 13, 537-544.

Sánchez Moreno, E. (2002a). Sociología y enfermedad mental. Reflexiones en torno a un desencuentro. Revista Internacional de Sociología, 31, 35-58.

Sánchez Moreno, E. (2002b). Individuo, sociedad y depresión. Málaga, Spain: Aljibe.

Sánchez Moreno, E. (2004). Por una sociología de la enfermedad mental. Etiología. Cuadernos de Trabajo Social, 16, 49-71.

Sánchez Moreno, E., Álvaro, J.L., \& Garrido, A. (2000). Estrés y salud mental: El papel de la posición social y las estrategias de afrontamiento. In J. Fernández del Valle, J. Herrero, \& A. Bravo (Eds.), Intervención psicosocial y comunitaria (pp. 397403). Madrid: Biblioteca Nueva.

Sánchez Moreno, E., \& Barrón, A. (2003). Social psychology of mental health: The social structure and personality perspective. The Spanish Journal of Psychology, 6, 3-11.

Sánchez Moreno, E., Garrido, A., \& Álvaro, J.L. (2003). Un modelo psicosociológico para el estudio de la salud mental. Revista de Psicología Social, 18, 17-33.

Sarason, I.G. (1988). Social support, personality, and health. In M.P. Janisse (Ed.), Individual differences, stress, and health psychology (pp. 109-128). NY: Springer-Verlag.

Sarason, B.R., Pierce, G.R., \& Sarason, I.G. (1990). Social support: The sense of acceptance and the role of relationships. In B.R. 
Sarason, I.G. Sarason, \& G.R. Pierce (Eds.), Social support: An interactional view (pp. 97-128). NY: Wiley.

Sarason, I.G., \& Sarason, B.R. (1985). Social support. Insights from assessment and experimentation. In I.G. Sarason \& B.R. Sarason (Eds.), Social Support: Theory, Research and Applications (pp. 39-50). Dordrecht, Holland: Martinus Nijhoff.

Sarason, I.G., Sarason, B.R., \& Pierce, G.R. (1992). Three contexts of social support. In H.O. Veiel \& U. Baumann (Eds.), The meaning and measurement of social support (pp. 143-154). NY: Hemisphere Publishing Corporation.

Sarason, I.G., Sarason, B.R., \& Shearin, E.N. (1986). Social support as an individual difference variable: Its stability, origins, and relational aspects. Journal of Personality and Social Psychology, 50, 845-855.

Seeman, T.E., Lusignolo, T.M., Albert, M., \& Berkman, L. (2001). Social relationships, social support, and patterns of cognitive aging in healthy, high-functioning older adults: McArthur studies of successful aging. Health Psychology, 20, 243-255.
Stoller, E.P., \& Pugliesi, K.L. (1991). Size and effectiveness of informal helping networks: A panel study of older people in the community. Journal of Health and Social Behavior, 32, 180-191.

Thoits, P. (1983). Multiple identities and psychological well-being: A reformulation and test of the social isolation hypothesis. American Sociological Review, 48, 174-187.

Thoits, P. (1995). Stress, coping, and social support processes: Where are we? What are next? [Extra issue] Journal of Health and Social Behaviour, 53-79.

Vaux, A. (1988). Social support: Theory, research and intervention. NY: Praeger.

Wills, T.A. (1985). Supportive functions of interpersonal relationships. In S. Cohen \& S.L. Syme (Eds.), Social support and health (pp. 61-82). Orlando, FL: Academic Press.

Received June 14, 2004 Revision received July 27, 2004 Accepted August 30, 2004 